\title{
Moulin Rouge. Nuevos códigos para nuevos tiempos
}

\author{
Lourdes López León \\ Universidad de La Laguna \\ lour.Ipz.In@gmail.com
}

RESUMEN: Moulin Rouge! (Baz Luhrmann, 2001) completa lo que su propio director ha dado a conocer como la «Trilogía del Telón Rojo». Muchos de los elementos de estilo característicos del cineasta -teatralización, mezcla de referentes, intertextualidad, fastuosidad en la puesta en escena o anacronismo musical- cristalizan en ella. Todos estos mecanismos no solo conforman el «estilo de telón rojo» de Luhrmann, sino también su condición de autor posmoderno. Un análisis detallado del filme y de sus procesos de producción permite observar cómo todo ello se manifiesta en la cinta, definida en el momento de su estreno como revitalizadora del género musical.

PALABRAS CLAVE: Cine musical, Teatralización, Posmodernidad, Intertextualidad, Baz Luhrmann.

\section{Moulin Rouge! New Codes for New Times}

ABSTRACT: Moulin Rouge! (Baz Luhrmann, 2001), completes what its director has called "The Red Curtain Trilogy». Many of the style elements that are the filmmaker's trademark - the theatrical conventions, the mixed references, the intertextuality, the lavish mise en scene or the musical anachronism - are crystalized in this film. All these devices, not only shape the Luhrmann red curtain style, but also shape his postmodern auteur condition. Through a detailed analysis of the film and its production process we can see how all of this is manifested in the picture. When it was released, the movie was also defined as a revitalization of musical genre.

KEYWORDS: Musical, Theatrical Conventions, Postmodernism, Intertextuality, Baz Luhrmann.

Recibido: 29 de marzo de 2016 / Aceptado: 8 de junio de 2016.

Un gran espectáculo, así puede entenderse el filme Moulin Rouge (Moulin Rouge!, Baz Luhrmann, 2001); un show esplendoroso puesto al servicio de un estilo musical milimétricamente pensado y donde todo parece encajar, a pesar de su manifiesta exageración.

Toda la cinta podría entenderse como un gran ejemplo de metalenguaje, ya que, desde los títulos de crédito, se sitúa al espectador en una sala de teatro, y se le hace asistir a una intrincada función del cabaret parisino. Sin embargo, atender solo a esto sería un error reduccionista, pues el filme es mucho más.

Considerado en el momento de su estreno como la renovación del género musical, habría que tener en cuenta que forma parte de una trilogía, que si bien no mantiene línea argumental alguna que atraviese las tres cintas, sí que presenta un estilo visual cohesionado y, sobre todo, autoconsciente por parte de sus creadores. El «estilo de telón rojo", definido así por el propio Luhrmann (The Red Curtain Trilogy) engloba El amor está en el aire (Strictly Ballroom, 1992), Romeo + Julieta de William Shakespeare (Williams Shakespeare's Romeo + Juliet, 1996) y Moulin Rouge. Son tres películas en las que el pastiche es evidente y en las que el director ha «utilizado las herramientas cinematográficas fusionadas con la impostación y el artificio del teatro» en lo que él mismo da a llamar «cine teatralizado» (Sartori, 2001).

Pero el «estilo de telón rojo» no se restringe únicamente al plano visual, sino que se manifiesta como una intrincada red donde cada nudo tiene una importancia y función concretas. Obviamente la visualidad es una de las características

LÓPEZ LEÓN, Lourdes: «Moulin Rouge. Nuevos códigos para nuevos tiempos», Boletín de Arte, n. ${ }^{\circ} 37$, Departamento de Historia del Arte, Universidad de Málaga, 2016, pp. 139-148, ISSN: 0211-8483. 
primordiales del cine; es, por tanto, lo que dentro del estilo Luhrmann más espectacularmente apabulla al espectador ${ }^{1}$.

Baz Luhrmann, y su amplio y leal equipo de colaboradores, es considerado en su país como un revitalizador cultural. Su productora, Bazmark, se ha convertido en la plataforma ideal para construir filmes con un fuerte y distintivo estilo personal, estilo que algunos autores consideran «basados en el pastiche y relacionados con el travestismo teatral» (Cook, 2010: 23-36).

Lo cierto es que Bazmark, es al mismo tiempo Bazmark Desing, Film, Live and Music, y el hecho de ocuparse de todos los aspectos de la producción de un filme, consigue dar a los mismos una sensación de empaque y de un cuidado acabado. La productora actúa a modo de compañía teatral u operística, valiéndose de escenarios "prestados", puesto que el rodaje de Moulin Rouge se realizó en cinco estudios de la Fox en Sidney, y con un maestro de ceremonias personificado en la figura de Luhrmann².

El estilo visual apabullante, la estética de colores saturados, el tipo de montaje acelerado..., forman parte del red curtain brand, pero también lo es la elección de los temas y su tratamiento. Una de las características que se traslucen como vitales para el cineasta australiano, es la necesidad de buscar la participación de la audiencia desde la propia temática de la cinta, adaptando un mito o fábula conocidos y localizándolo en un contexto novedoso y radicalmente opuesto al original. Así, Moulin Rouge rescata un mito griego, Orfeo y Eurídice; pero el Orfeo moderno (el joven Christian, interpretado por Ewan McGregor) desciende, ya no al Hades clásico, sino a un infierno contemporáneo: los bajos fondos parisinos de fines del siglo XIX, Montmartre y el Moulin Rouge, para rescatar a su amada Eurídice (Nicole Kidman como la cortesana Satine). A ese significativo mito, se fusionan otras dos referencias de la literatura y la ópera: La dama de las camelias (Alejandro Dumas, 1848) y La Bohème (Giacomo Puccini, 1896), ambas desarrolladas en el París finisecular.

Toda esta amalgama de influencias, así como el énfasis en la búsqueda de un estilo propio y distintivo, responde al propósito de reinvención del género musical por parte de Baz Luhrmann, y que cristaliza en la tercera película de la trilogía. Pero la revitalización de un género no atañe en este caso únicamente a los problemas temáticos; el cineasta prefiere centrar su atención en las cuestiones de estilo con la intención de «crear nuevos códigos para nuevos tiempos». Lo que preocupa a Luhrmann no es el fondo, puesto que las historias no han variado tanto desde los primeros musicales:

Cuando hablo de códigos, me refiero a la forma. Astaire y Rogers en los 30, Julie Andrews en los 60, Joel Grey y Liza Minelli en los 70 y John Travolta en los 80 bailaban y cantaban historias de amor similares de forma distinta [...]. Para mí, el reto ha sido encontrar mi propio código y adaptarlo (Sartori, 2001).

Es interesante observar cómo ese nuevo y particular código se basa en una amalgama de referentes anteriores ${ }^{3}$; la tradición musical (hollywoodense y bollywoodense) proporciona al director las claves para, desfigurándolas y deformándolas cual escultura barroca ${ }^{4}$, crear un estilo musical que sirva a sus propósitos. De ese modo encontramos que el «estilo de telón rojo» muestra una serie de características fácilmente identificables en la cinta. A la gran inspiración del musical estadounidense e indio, habría que añadir un fuerte intento de integración entre arquitectura (la propia de los decorados del filme) y música, y la utilización de grandes éxitos del pop y del rock versionados como banda sonora para el filme; hecho este que vuelve a buscar de nuevo la participación de la audiencia, puesto que son canciones populares fácilmente reconocibles por los espectadores.

\section{Herencia del género musical}

A pesar de la aparente modernidad que destila, Moulin Rouge resulta de una interesante mezcolanza de la tradición del género musical. A las referencias más evidentes y reconocidas por el cineasta, tales como Moulin Rouge (John Huston, 1953), French Cancan (Jean Renoir, 1955), Las zapatillas rojas (The Red Shoes, Michael Powell, Emeric Pressburguer, 1948) o el estilo musical de la MGM; habría que añadir otras, quizá menos claras, pero perfectamente observables en el filme.

Así, la presentación de Satine en el cabaret con el número «Sparkling Diamonds» [1], podría recordar a la Lola-Lola de Marlene Dietrich en El ángel azul (Der Blaue Engel, Josef von Sternberg, 1930) [2]. Si bien las relaciones más evidentes se establecen a nivel de vestuario -que 
remite también a Liza Minelli en Cabaret (Bob Fosse, 1972) y a Marilyn Monroe en Bus Stop (Joshua Logan, 1956)-, es curioso observar cómo las letras que ambas interpretan en sus números iniciales las definen como mujeres en apariencia independientes, que atraen a los hombres hacia ellas movidas por un interés puramente material. Satine es un personaje creado a partir de muchos otros; así, en otro momento de la cinta, se presentará con un traje ciertamente inspirado en Gilda (Charles Vidor, 1946), e incluso la actitud del personaje rememora al de Rita Hayworth, al quitarse los largos guantes negros.

Con todo, no es únicamente en el personaje en el que se logran observar las reminiscencias clásicas. Las alusiones también se hacen patentes en la puesta en escena de números musicales concretos, donde se acude al estilo claramente identificable de Busby Berkeley [3]. Las coreografías caleidoscópicas y por estratos, rodadas desde planos cenitales y planos generales, tan características del coreógrafo estadounidense, pueden observarse en "Like a Virgin» [4] o "Hindi Sad Diamonds".

Con respecto a estos dos números además, es interesante añadir otro tipo de influencias cinematográficas contemporáneas. Por un lado, la versión de «Like a Virgin» interpretada por Jim Broadbent y Richard Roxburg en el escenario de la Torre Gótica, llega a convertir el éxito de Madonna en una pieza de entretenimiento de canto y bai-

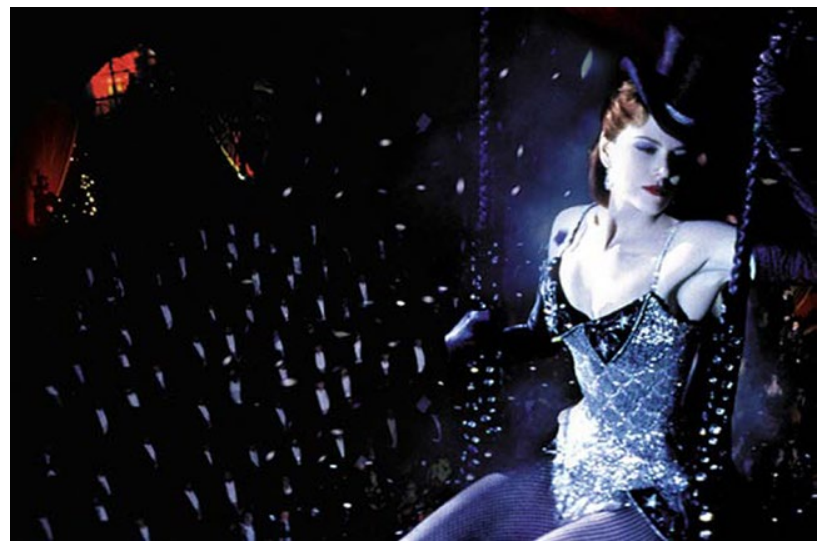

1. Presentación de Satine en el Moulin Rouge

le al más puro estilo Hello, Dolly! (Gene Kelly, 1969). Por su parte, "Hindi Sad Diamonds» combina a la perfección la influencia americana con una fuerte impronta de los musicales de Bollywood 5 .

La influencia bollywoodense es apreciable a distintos niveles. Indudablemente, Luhrmann realiza un verdadero homenaje al cine indio incluyendo la canción «Chamma Chamma», que formaba parte de la película China Gate (Rajkumar Santoshi, 1998), en su número final, Hindi Sad Diamonds.
2. Caracterización de Marlene Dietrich como Lola-Lola para El ángel azul

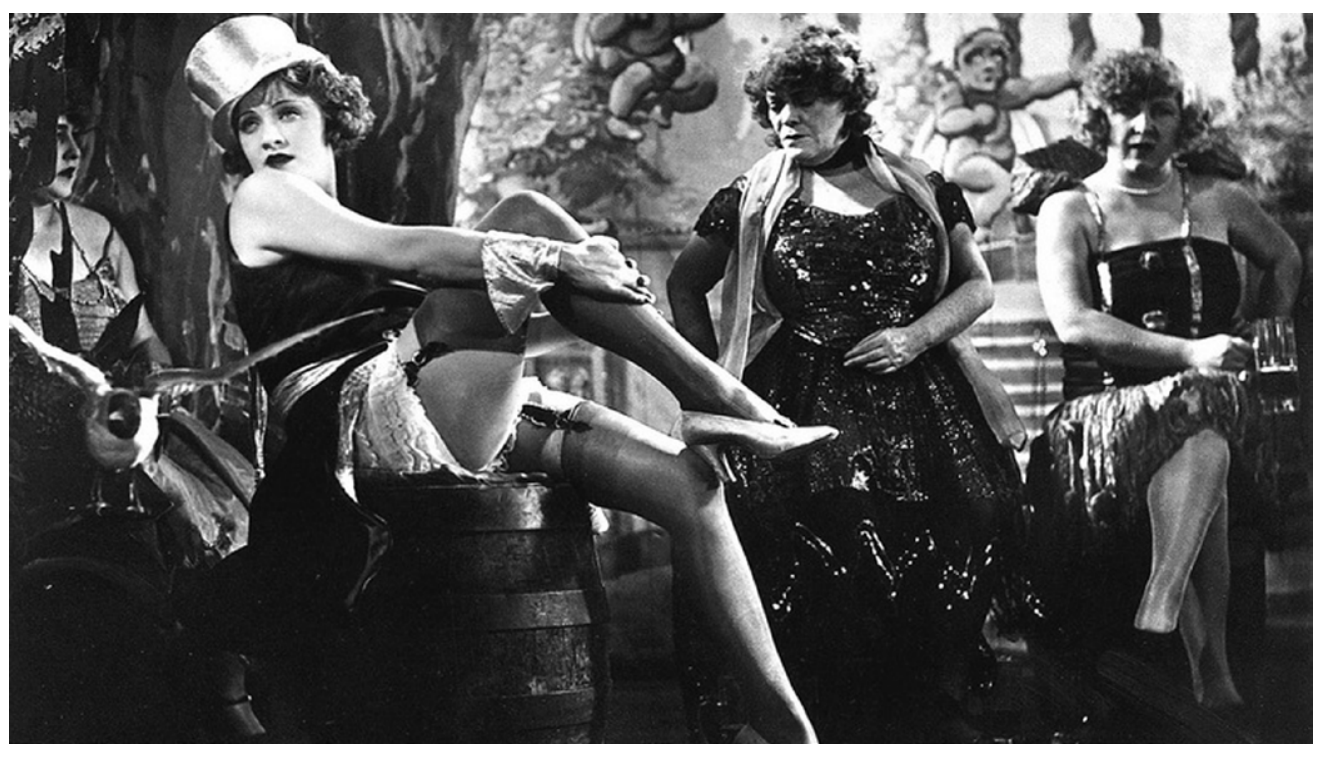




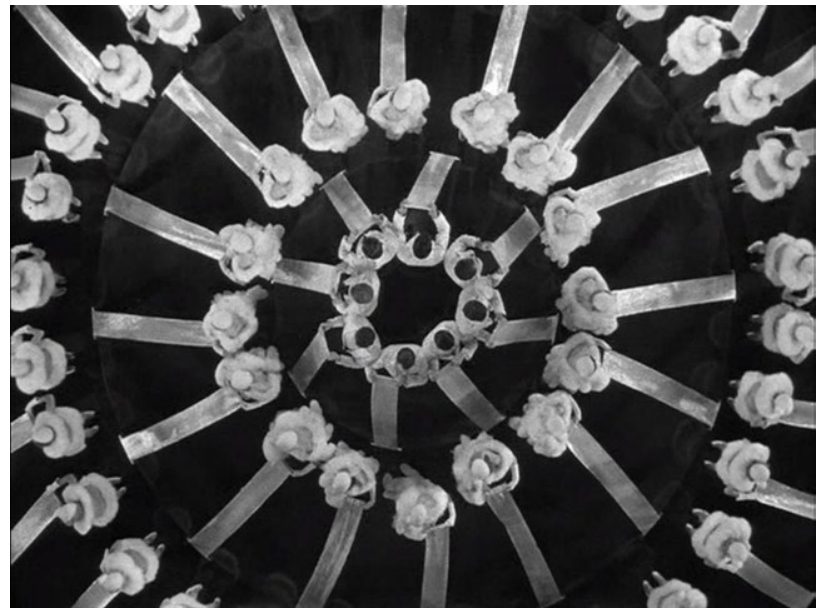

3. Coreografía de Busby Berkeley para La calle 42 (42 ${ }^{\text {nd }}$ Street, Lloyd Bacon, 1932)

Si bien puede que el filme de Santoshi no fuera ampliamente conocido en Occidente, sí lo fue el videoclip extraído del mismo, que se hizo famoso gracias a los bailes de Urmila Matondkar [5]. En el número final de Mouling Rouge, no solo se hace uso del tema musical, sino que además, el propio vestuario de Kidman es fiel heredero del que lucía Matondkar en la película hindi [6].

5. Urmila Matondkar en China Gate (Rajkumar Santoshi, 1998)

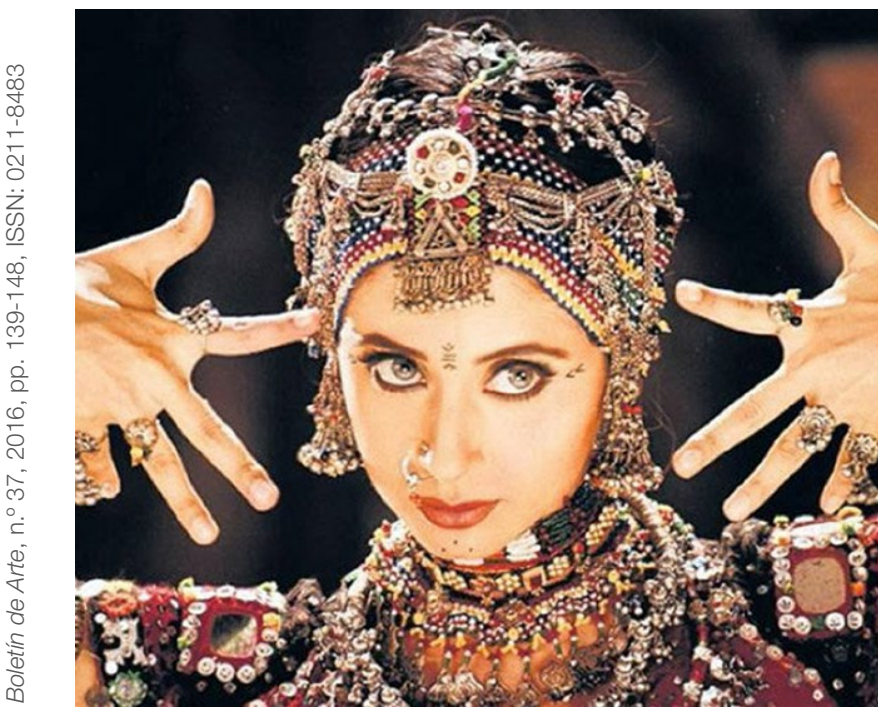

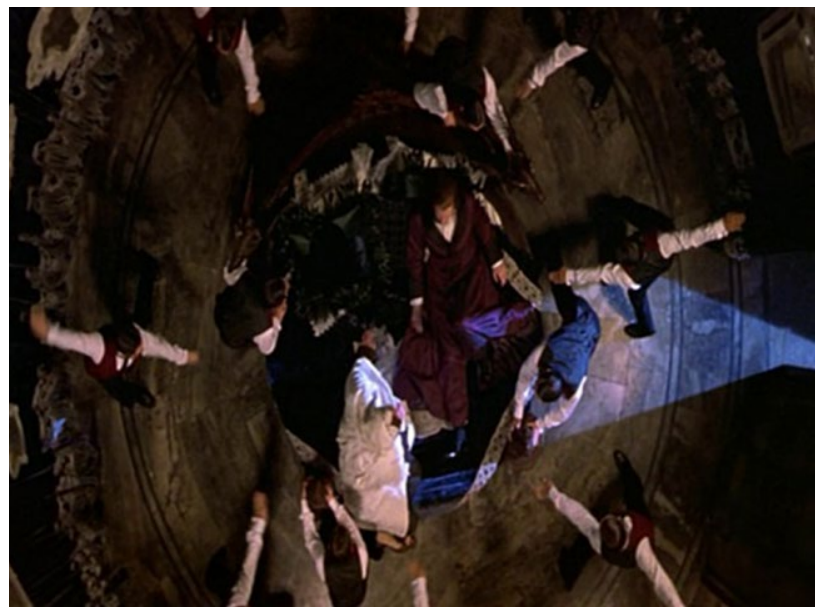

4. Plano cenital del número «Like a Virgin» al estilo de Busby Berkeley

Sin embargo, Luhrmann acude a esa secuencia concreta de la cinta pero no trata sus números del modo en que lo hace el cine indio. Bollywood no pretende que el baile y la música se integren en el argumento de la película, las canciones se componen pensando en generar expectación alrededor de la misma. El «número musical» es «la manera que tiene Bollywood de reflejar la actitud india hacia la sensualidad y la moralidad» (Amin, 2009). Por su parte, el musical del cineasta australiano, aunque en un principio pudiera parecer un musical entre bastidores, acaba resultando un musical integrado, donde las canciones aportan información y ayudan a que la historia avance. El canto y el baile se convierten en un dispositivo narrativo más, son, en palabras del compositor Craig Armstrong, «elementos estructurales que refuerzan la narración» (Luhrmann, 2002).

No obstante, las reminiscencias bollywoodenses son apreciables también a otros niveles. No afectan tan solo a la música escogida, sino que además empapan el guion y el diseño visual. A nivel narrativo, la trama melodramática del filme recuerda a los argumentos indios. Además, el show que los bohemios preparan para presentar en el cabaret, gira en torno a una historia trágica entre un malvado maharajá que intenta ganarse el amor de una cortesana, quien a su vez está enamorada secretamente de un tañedor de sitar; situación que no es más que la metáfora del triángulo amoroso establecido entre Christian, Satine y El Duque. 
A nivel visual, las influencias se aprecian en la utilización de colores muy saturados, en el énfasis de los actores por realizar interpretaciones eufóricas, y por un estilo de edición muy rápido 6 (Coyle, 2013: 9-30), que también tiene que ver con un cierto estilo videoclipero, pues «el terreno del vídeo musical es el más idóneo para la creatividad y experimentación audiovisual, puesto que, al no depender de una estructura narrativa [...] ofrece la posibilidad de desplegar en él los más vanguardistas recursos cinematográficos» (Gubern, 1995: 465).

También habría que destacar la importancia de la puesta en escena, donde de nuevo los elementos hindúes están presentes. Estos elementos no solo aparecen en el ya comentado número final, sino que decoran uno de los espacios clave de la película: el elefante. La estética india (cuadros, cortinajes o lámparas de gusto oriental, muy de moda entre la burguesía francesa finisecular) está presente tanto en el exterior como en el interior de la enorme escultura. E incluso, allí será representado por primera vez el show bohemio Spectacular, Spectacular; jugando de nuevo magistralmente con el metalenguaje, los personajes hacen uso de los elementos decorativos para su improvisada representación.

Es este uno de los momentos en que la integración entre arquitectura y música se hace más evidente. Sería interesante tener en cuenta el afán de perfeccionismo que domina la creación de los espacios donde se desarrollan las historias. Los sets de Moulin Rouge fueron ciertamente fastuosos, una mezcla de decorados a escala real, miniaturas, recreaciones digitales y $3 \mathrm{D}$ y cristal mate.

\section{Puesta en escena musical}

Si bien es cierto que, aunque todo se base en hechos históricos es un mundo pasado por el filtro contemporáneo, todo funciona dentro de los parámetros del filme. No se pretendía en ningún momento realizar una recreación histórica del cabaret, ni del Montmartre del momento; por lo tanto, sí es cierto que el equipo podía utilizar cualquier elemento disponible en 1890, pero era completamente lícito hacerlo fuera de contexto.

Así, el filme se desarrolla en tan solo cuatro espacios, invadidos de una fuerte sensación de mundo inventado: la

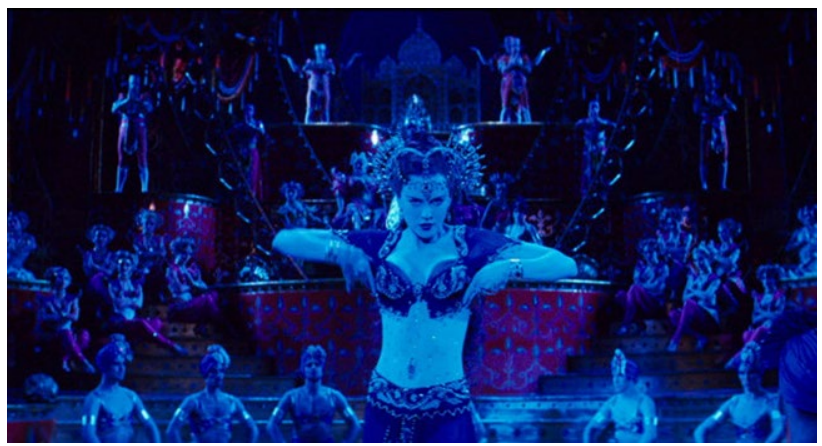

6. Número final «Hindi Sad Diamonds»

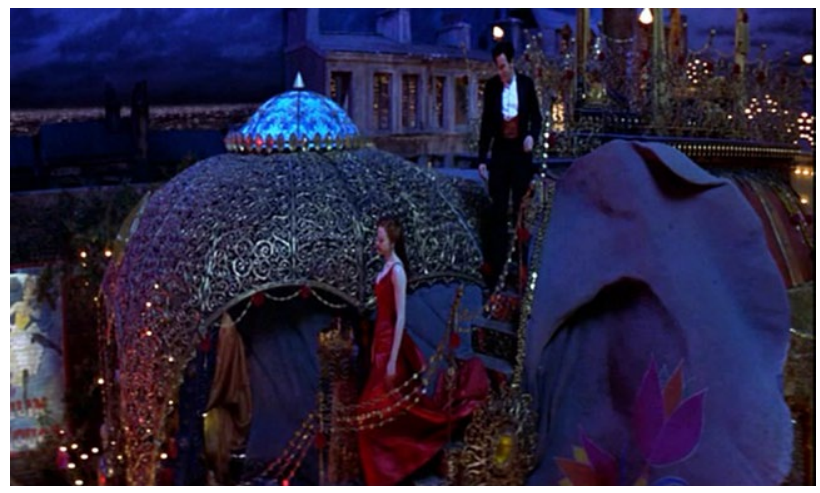

7. Uso metafórico de la escalera durante el número «Elephant Love Medley»

pensión donde viven Christian y los bohemios; el interior del club, el elefante ubicado en el jardín y la Torre Gótica. A estos espacios habría que añadir la calle principal frente al cabaret y el París del momento, que solo se muestra en detalle al principio del filme, mediante una maqueta en gran parte de creación digital. Desde una imagen fija de la misma, a modo de postal de época, la cámara viaja a través de ella hasta llegar a Montmartre e introducirse en sus calles. Resulta curioso observar cómo la puerta de entrada a este barrio de pecado la constituye la boca de un monstruo [8]. Es esta una referencia a la época: la transposición de la entrada de un conocido cabaret parisino, el Club Inferno [9], que asimismo remitía tanto a la puerta de entrada del Palacio Zuccari de Roma, como a la escultura del monstruo de Pirro Ligorio del Jardín de Bomarzo. 


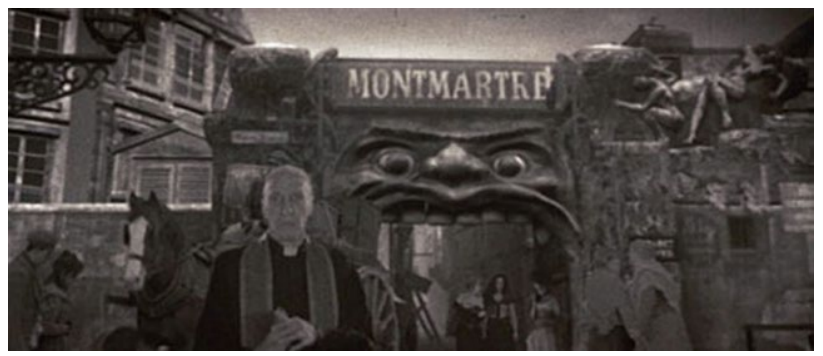

8. Puerta de entrada, en el filme, al barrio de Montmartre

El cabaret original contaba con tres partes: el molino, el jardín y el salón de baile. Tres de los números musicales más contundentes, y elementales para el desarrollo dramático de la trama, se exhiben en ellas: "Elephant Love Medley», «El Tango de Roxanne» y «The Show Must Go On», secuencias en las que el despliegue de recursos cinematográficos se torna casi abrumador.

Si hay un escenario donde la artificialidad se pone más de manifiesto, ese es el elefante; un complejo decorado creado a tamaño real (18 m) para que se actuara encima, y que contó además con varios modelos a escala. «Elephant Love Medley» se desarrolla en el vientre, la cabeza y el lomo del animal; mediante el uso de planos tomados desde den-

\section{Entrada al Club Inferno}

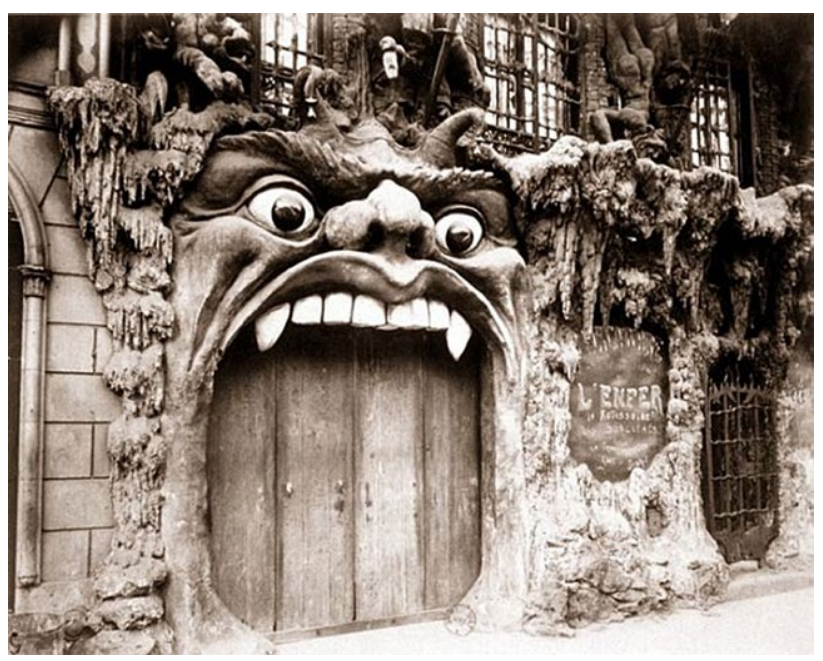

tro y fuera del mismo, el espectador es capaz de apreciar y abarcar el decorado en su totalidad, aunque habría que decir que la secuencia es una combinación de miniaturas, un plató a nivel del suelo para los primeros planos y planos medios de la pareja, cristal mate y el elefante a escala real. Este escenario ya había aparecido, en su interior, cuando Christian enamora a Satine con "Your Song» y ambos «vuelan» sobre París al más puro estilo de los musicales hollywoodenses de los años 30.

En esta secuencia, sin embargo, ellos se reconocen primero desde sus espacios individuales (él en su buhardilla, ella en el cabaret), siendo el elefante el elemento de unión entre ambos. Satine asciende a su lomo, desde donde puede contemplar la ciudad, metáfora de todo lo que le está vedado (incluyendo también el amor). Si en la barriga del animal había nacido el amor, ahora ambos se encontrarán en el lomo, y es en este espacio donde el personaje interpretado por McGregor intentará convencerla con un medley de clásicos del pop, estableciéndose un diálogo cantado entre ambos.

El escenario se convierte entonces en metáfora de sus sentimientos. Cuando Christian habla de la capacidad del amor para elevarlo, sube a la cabeza del paquidermo, se acerca a los límites físicos del decorado aludiendo a lo ilimitado de ese sentimiento. De manera antagónica a como él se abre, ella se cierra en sí misma bajando las escaleras para esconderse de nuevo en el interior; de este modo, jugando con la arquitectura, el personaje de Nicole Kidman no solo se oculta físicamente sino que también lo hacen sus sentimientos ${ }^{8}$ [7]. Será en el clímax de la escena, en el momento en que ella se rinda, cuando la cámara los recorte a ambos sobre la ventana en forma de corazón; es de nuevo en esa habitación en la que ya había surgido el sentimiento, y finalizando con el mismo tema de Elton John, donde puede volver a materializarse, ahora ya de un modo más fehaciente y consciente por parte de ambos.

El «Tango de Roxanne», por su parte, rompe con el espíritu romántico creado hasta ahora en la cinta, oscureciendo la trama y aportando un tinte trágico. En la puesta en escena del número destacan varios elementos, entre los que sobresale la utilización de la luz en este ambiente, que se corresponde con la sala ubicada tras el molino. El uso de este espacio quizá hace que el baile se presente como un número musical no espontáneo, sino creado ex profeso para ser re- 
10. Utilización de luz dramática mediante focos teatrales para el "Tango de Roxanne»

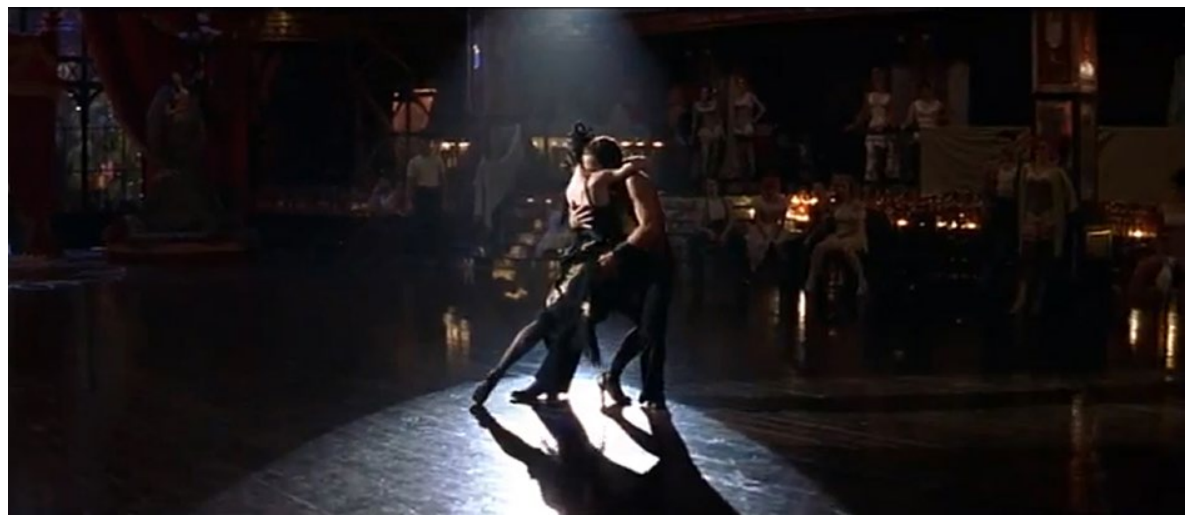

presentado allí; sin embargo, el Argentino comienza a contar la historia de Roxanne en ese preciso instante para explicar al poeta el peligro de enamorarse de una mujer como Satine.

Mediante la utilización de un montaje paralelo, que parece seguir el compás de 4/4 típico del ritmo porteño, se produce un trasvase entre la historia que se baila y lo que sucede en la Torre Gótica. De modo similar a como en el tango el hombre fuerza a la mujer a bailar siguiendo sus pasos, el Duque fuerza a Satine a satisfacer su pasión; el canto pierde aquí importancia (si bien la letra de Sting, a la que se superponen las melodías de "Tanguera» de Mariano Mores, resulta esclarecedora) dando paso a la danza como narradora de la historia. La iluminación se torna mucho más oscura que en el resto del filme, haciendo uso de focos teatrales en vez de cinematográficos, para crear una iluminación dramática muy dura, con fuertes sombras que van guiando los pasos de los bailarines [10].

A pesar de tratarse de un espacio muy amplio, el Argentino se apropia de él al completo, utilizándose la luz para transmitirlo visualmente. Pero a pesar de remitir al tango bonaerense el número está rodado al estilo de Hollywood, con una coreografía perfectamente estudiada y un espacio que respira palpablemente, no como los atestados quilombos de los arrabales argentinos donde nació el baile. Este es tratado además de un modo operístico, no solo a nivel de danza sino también en el entramado musical, la complicación orquestal y la utilización de tesituras contrastadas, utilizándose para el personaje más sombrío del Argentino a un barítono, y para los protagonistas voces más luminosas: tenor de Ewan McGregor y soprano de Nicole Kidman.
El desarrollo del baile va in crescendo a medida que se desarrolla también la escena en la Torre. A un primer momento apaciguado, de confianza entre las parejas, con unos pasos de tango circulares y entrecruzados que encuentran su símil en los movimientos seguros y fiables de la cortesana en la Torre, le sigue un ritmo más acelerado, metáfora de una traición y unos celos más que evidentes cuando Nini (Roxanne) se eche en brazos de los hombres que la rodean. Casi queriendo dar a entender que es este un sentimiento universal y común en ese mundo, se unen al baile varias parejas, realizando con exactitud los mismos pasos de tango.

Cuando Christian abandona el salón y sale al jardín para descubrir a Satine en el balcón de la torre, la luz vuelve a cargarse de significado y, mientras ella es iluminada en azul, color frío que habla de su propia frialdad fingiendo ante El Duque, él aparece rodeado de una tonalidad roja, fruto de la rabia y los celos que le acometen. Asimismo se le enmarca con un plano picado ligeramente inclinado, metáfora de su inestabilidad e impotencia ante la situación.

El tango por su parte continúa detrás, y culmina cuando todos los hombres rodean a Nini, del mismo modo que El Duque asedia y fuerza a Satine. La muerte metafórica de Roxanne a manos del Argentino, con un montaje acelerado, se realiza en el ataque de Chocolat al Duque para socorrer a Satine, dando así por concluido el número de un modo contundente ${ }^{9}$.

El «telón rojo» de Luhrmann ha sido desplegado ostentosamente, y culminará en el suntuoso número final; sin embargo, sería interesante tratar otro número más sobrio pero llamativo a nivel de integración de música y arquitectura. 
"The Show Must Go On» se muestra con un montaje mucho más lento que los anteriores, y responde enteramente a un tratamiento operístico.

La secuencia comienza entre bastidores, en el camerino de Satine, donde Zidler le ha revelado que se muere de tuberculosis, y que si no aleja a Christian, el Duque lo hará asesinar. El teatro se prepara para el estreno del espectáculo, y Satine ha de prepararse para representar otro show ante el escritor, hasta tal punto la vida de los personajes del Moulin Rouge depende de la pantomima.

La miseria con que se presentan los bastidores (falta de luz y de un mobiliario conveniente) sirve para magnificar el esplendor y el artificio del escenario. La oscuridad de las bambalinas representa también las sombras que, a nivel emocional, atormentan a Satine, al igual que la jaula con el pájaro, en primer término ante ella, simboliza su incapacidad para escapar de ese mundo. Desde la parte baja del cabaret, la cámara realiza un travelling con Zidler, que va recorriendo la tramoya mientras empieza a cantar el clásico de Queen; a él se unirá un coro de mujeres, relatando con la letra de la canción los sacrificios de una vida dedicada al espectáculo. Con un montaje lento, y una puesta en escena sobria, el propietario llega tras las puertas del escenario en el momento en que canta, casi para sí mismo, que el espectáculo debe continuar, abriéndose entonces con fuerza las puertas y mostrando la magnitud y amplitud del escenario y la claridad del salón a la luz de la mañana, hacia la que Zidler se dirige como metáfora de un renacer.

El personaje de Harold se muestra aquí como supervisor, vigilando que todo esté listo para el estreno, que cada elemento y cada persona estén en su lugar. Satine es una de esas personas que ha de ocupar su posición, es la encargada de restablecer el orden perdido en el mundo del cabaret, y así aparece durante el número. Primero ante el espejo, construyendo su pantomima, para luego recorrer la tramoya al igual que Zidler; pero Satine sale al escenario con una fuerza distinta, el telón cae tras ella y un foco la ilumina en contrapicado, realzando su importancia y su fuerza dentro de la trama y encima de ese escenario, que subraya una altivez muy lejana al sentimiento interior del personaje. También ella se dirige a la puerta, a la luz de un nuevo día, donde se encuentra Harold y de nuevo, la autoridad del propietario se refleja tan solo con su presencia, a la que Satine ha de someterse.
Al espectador le ha sido expuesta la columna vertebral del teatro, haciendo a los personajes deambular por sus estructuras internas; pero, al mismo tiempo, también se ha expresado sin tapujos la realidad de la vida de sus moradores a través de la letra de la canción, que parece aludir por igual a la pantomima teatral y a la de nuestra existencia. Al igual que la ópera funciona si canto y decorados se integran a la perfección formando un todo, aquí el número musical sobresale no solo por esa perfecta unión, sino también por la precisión y sobriedad con que se realiza.

\section{Estilo musical anacrónico}

El número anterior buscaba también la participación del público a través del tema de Queen. Baz Lurhman consideraba que utilizar música contemporánea haría que el púbico se identificara con el musical: es en ese sentido que se puede hablar de cine de participación del público. La clave por tanto está en utilizar todas las influencias musicales en un popurrí que definía en parte la cultura fin de siglo. El uso de canciones preexistentes y fácilmente reconocibles, se manifiesta como otra de las clave del «estilo de telón rojo»"10.

La música, entonces, sirve a varios propósitos: hacer avanzar la historia y atraer a la audiencia. Pero el filme de Luhrmann es muy potente a nivel visual, por ello la parte musical debe equilibrarlo de manera igual de poderosa. Para conseguirlo no se acude a un estilo musical lineal y concreto, por el contrario: al igual que las referencias cinematográficas resultan de una amalgama, la música es tratada de un modo totalmente ecléctico, y se acude a grandes clásicos del pop y del rock, versionados en clave roquera, operística, dance, hip-hop o tanguera. En cierto modo, y como ha reconocido el propio director, se trataba de traer el cabaret francés a los clubes nocturnos actuales. En ese sentido, una gran influencia fue el mundo creado en Manhattan por el club Studio 54 y su heterogeneidad, tanto a nivel musical como en el tipo de público al que atraía. Esto se evidencia en el número inicial de presentación del cabaret como un club de ambiente fuertemente hedonista donde todo y todos tienen cabida.

Podría decirse que la banda sonora de Moulin Rouge! se compone de temas «reciclados» pero también reinventados, puesto que todas las canciones han pasado por un complejo proceso de versionado. Esos procesos han sido, 
básicamente, dos: por un lado, muchos de los números están basados en medleys: una composición musical formada por fragmentos de obras diversas que se interpretan una detrás de otra o superpuestas. Por otro lado, el proceso más utilizado ha sido el mash-up, un método estilísticamente más libre, basado en la combinación y superposición de dos o más temas para crear una nueva canción en una especie de collage. Este tipo de proceso de yuxtaposición musical al que tiende Luhrmann es muy común en los géneros hip-hop, R\&B, soul o la música electrónica. Llevado al ámbito cinematográfico tiene en Moulin Rouge! a su mayor y mejor exponente, siendo sus artífices el compositor Craig Armstrong (orquestación), el director musical Marius de Vries y el Dj Fatboy Slim, encargado de realizar muchos de los collages musicales a partir de pequeños loops. El uso sistemático del mash-up permitió reinterpretar temas actuales de una manera romántica, y también actualizar temas antiguos usando muestras y yuxtaposiciones.

De igual modo, la elección del anacronismo en el ámbito musical y la reinterpretación de la historia desde elementos actuales, se vislumbra en las características elegidas en la planificación y montaje cinematográficos. El estilo de montaje deriva visiblemente del utilizado en los vídeos musicales, lo que implica movimientos de cámara donde predomina la espiral o remolino, saturación visual o estética de la fragmentación. El predominio en el filme de esos rasgos de estilo videoclipero es lo que permite hablar de esa influencia, donde el montaje final acaba resultando frenético y alocado ${ }^{11}$.

Tras todo lo expuesto anteriormente, y a modo de conclusión, podría dar la sensación de que el estilo de Baz Luhrmann, con todas sus referencias, influencias, reinterpretaciones y apropiaciones, se caracteriza precisamente por la falta de estilo. Lo cierto es que no se puede aislar al cineasta de las corrientes artísticas de la contemporaneidad, y es precisamente esa sensación de refrito de sus filmes una de las características propias de la posmodernidad. Como musical posmoderno, Moulin Rouge! resulta una suerte de caos, hacia el que tiende este movimiento, que además tiene en el collage y el pastiche una de sus referencias, así como la plena libertad para moverse entre estilos y para deconstruir y reinterpretar desde una perspectiva personal.

El arte posmoderno se define por la indefinición. Aun así, y aunque pudiera parecer contradictorio, el estilo es un factor vital en la cinematografía contemporánea, utilizado para asociar un producto con un director o estudio concretos. Así, Luhrmann se apropia de la hibridación posmoderna para crear un sello, una firma que lo define y lo diferencia dentro del panorama cinematográfico actual como un innovador artístico.

\section{Notas}

1 Lipovetsky (2009) comenta el fenómeno del cine hipermoderno (para él un fenómeno inabarcable por el término «posmoderno") y sus tres pilares básicos: la hiperbolización o estética del exceso, la desregulación y aumento de la complejidad formal y la multurreferencialidad. Moulin Rouge participa de estos tres procesos «híper», poniendo especial énfasis en el exceso y la exuberancia.

2 Pam Cook (2010: 23-36) trabaja el fenómeno del cine transnacional, analizando la filmografía y modos de producción de Baz Luhrmann como paradigmas de estos nuevos procesos cinematográficos globales.

3 En este sentido Gilles Lipovetsky (2009: 139) comenta que la multirreferencialidad «es entretenimiento para el nuevo espectador que se divierte reconociendo los guiños; para los realizadores se trata de disfrutar cultivando las citas, las asociaciones humorísticas y asimétricas de segundo nivel.»

4 Es con respecto a la deformación que podemos aplicar los términos de «barroco» o «manierista», un retorcimiento de los elementos, en este caso cinematográficos, que rompe con la estética clásica. Asimismo, la idea de telón ya estaba muy presente en el arte barroco, un arte de ocultamiento de la realidad tras un telón fastuoso.

5 Sin embargo, como apuntan Jordi Balló y Xavier Pérez (1997: 11), la pertenencia a una cadena creativa no debe entenderse como una limitación. «Muy al contrario, lo que hace el cine es evocar los modelos narrativos anteriores con una puesta en escena que provoca que una determinada historia resulte nueva, fresca, recién inventada, y sugiera una manera contemporánea de entender una trama ya evocada en algunas de las mejores obras del pasado".

6 Resulta curioso observar cómo a veces las influencias realizan un movimiento similar al de un boomerang. Bollywood inspiró a Luhrmann a la hora de idear su filme, y unos años después, la influencia de Moulin Rouge! se dejó notar en la cinta india Sueños de estrella (Om Shanti Om, Farah Khan, 2007).

7 El Moulin Rouge original contaba con un elefante que había sido recuperado de la Exposición Universal de 1889 y que albergaba un club árabe con espectáculos de danza del vientre y un fumadero de opio.

8 La escalera supone una metáfora que puede ser interpretada de varios modos: ascender por ella lleva a las mieles celestiales, mientras que descender conduce a lo terrenal, y es símbolo de recogimiento. Sin embargo, aquí actúa también como escenario de la declaración amorosa y como distancia; plantea la dificultad amorosa en términos espaciales, la arquitectura como manifestación de las complicaciones de un amor prohibido. Para mayor profundización véase Balló (2000).

9 Cabría aquí un pequeño comentario acerca de personajes que aparecen en el filme y que responden a personas que históricamente existieron en el Moulin Rouge. Chocolat era un bailarín negro, famoso en el cabaret por su color de piel. Por su parte Harold Zidler se inspira en el cofundador del club, Charles 
Zidler. Toulouse está inspirado en el pintor Henri de Toulouse-Lautrec; resulta interesante reseñar que algunas de las frases que su personaje esgrime en la película, fueron tomadas de cartas escritas por el propio pintor.

10 También podría conectarse, en este sentido, el musical australiano con la tradición de la ópera-rock, muy de moda en los años 70 gracias a las transformaciones musicales que se sucedían en esos momentos. La utilización anacrónica de la música popular para contar historias (caso de Jesucristro Superstar, Norman Jewison, 1973) fue una de sus características, como comenta García Gómez (2009: 43-139).

11 En referencia a vídeo-clip y el cine véase García Gómez (2009: 43-139).

\section{Bibliografía}

AA.W. (1995), Historia general del cine. El cine en la era del audiovisual, vol. XIl, Cátedra, Madrid.

AMIN, Tushar (2009), Made in Hollywood, Océano, Barcelona.

ARAGÓN PANIAGUA, Tatiana (2007), «Un ejemplo de postmodernidad cinematográfica: la estética del pastiche en Moulin Rouge (Baz Luhrmann, 2001)", Boletín de Arte, n. ${ }^{\circ} 28$, pp. 451-477.

BALLÓ, Jordi y PÉREZ, Xavier (1997), La semilla inmortal. Los argumentos universales en el cine, Anagrama, Barcelona.

BALLÓ, Jordi (2000), Imágenes del silencio. Los motivos visuales en el cine, Anagrama, Barcelona.

COOK, Pam (2010), «Transnational Utopias: Baz Luhrmann and Australian Cinema», Transnational Cinemas, 1.1, pp. 23-36.

LIPOVETSKY, Gilles y SERROY, Jean (2009), La pantalla global. Cultura mediática y cine en la era hipermoderna, Anagrama, Barcelona.

LOSILLA, Carlos (2003), La invención de Hollywood. O cómo olvidarse de una vez por todas del cine clásico, Paidós, Barcelona.

GARCÍA GÓMEZ, Francisco (2009): «El hijo marchoso del cine: relaciones e interdependencias entre el cine y el videoclip», en SÁNCHEZ LÓPEZ, Juan Antonio y GARCÍA GÓMEZ, Francisco (coords.), Historia, estética e iconografía del videoclip musical, Universidad de Málaga, Málaga, pp. 43-139.

SARTORI, Beatrice: «Baz Luhrmann: He querido reinventar el musical», en El Cultural (Octubre, 2001) «http://www.elcultural.com/revista/ cine/Baz-Luhrmann-He-querido-reinventar-el-musical/1173» (fecha de consulta: 07- 09- 2015). 